\title{
Spontaneous Breathing Patterns of Very Preterm Infants Treated With Continuous Positive Airway Pressure at Birth
}

\author{
ARJAN B. te PAS, PETER G. DAVIS, C. OMAR F. KAMLIN, JENNIFER DAWSON, COLM P. F. O’DONNELL, \\ AND COLIN J. MORLEY \\ Division of Newborn Services [A.B.P., P.G.D., C.O.F.K., J.D., C.J.M.], Royal Women's Hospital, Carlton, Victoria 3053, Australia; \\ Department of Neonatology [C.P.F.O.], National Maternity Hospital, Dublin 2, Ireland
}

\begin{abstract}
There are no data describing how very preterm infants breathe spontaneously immediately after birth. We studied a convenience sample of spontaneously breathing infants $\leq 32$ wk' gestation treated with facemask continuous positive airway pressure at birth. Airway pressure and flow were measured and each breath analyzed. Twelve infants had 792 breaths suitable for analysis. Results are given as mean (SD). Gestational age and birth weight were 29 (1.9) wk and 1220 (412) g. Recordings were started 159 (77) s after birth. The inspiratory pattern and duration was similar in all breaths at 0.36 (0.11) s. There were five expiratory patterns; most infants had more than one. In $79 \%$ of breaths expiratory duration (1.6 (1.1) s) was slowed or held by interruption or braking of expiratory flow. It was braked in $47 \%$ to a complete expiratory hold, in $22 \%$ by grunting or crying, and in $10 \%$ by slow or interrupted expiration. In $21 \%$ of the breaths, expiration was not interrupted and lasted $0.53(0.13) \mathrm{s}$. Half of these breaths represented a panting pattern (rate $>60 / \mathrm{min}$ ). Immediately after birth, most very preterm infants, treated with continuous positive airway pressure, frequently prolong their expiration by braking the expiratory flow. (Pediatr Res 64: 281-285, 2008)
\end{abstract}

$\mathrm{V}$ ery preterm infants may have difficulty aerating their lungs after birth because of poor respiratory drive, weak muscles, flexible ribs, surfactant deficiency, and impaired lung liquid clearance (1-4). However, many very preterm infants treated immediately after birth with continuous positive airway pressure (CPAP) breathe well and achieve normal blood gases $(5,6)$.

Between 1960 and 1986, observational data were gathered immediately after birth from small numbers of spontaneously breathing term infants and used to inform international guidelines for neonatal resuscitation (7-14). There are no data describing how very preterm infants breathe and aerate their lungs immediately after birth. It may be inappropriate to assume the results of studies of term infants also apply to very preterm infants.

The aim of this study was to investigate the spontaneous breathing patterns of very preterm infants treated with CPAP immediately after birth.

Received March 3, 2008; accepted April 18, 2008.

Correspondence: Arjan B. te Pas, M.D., Division of Newborn Services, Royal Women's Hospital Melbourne, 132 Grattan Street, Carlton, VIC 3053, Australia; e-mail: a.b.te_par@lumc.nl

AtP is recipient of a Ter Meulen fund grant for working visits, Royal Netherlands Academy of Arts and Sciences, The Netherlands.

\section{PATIENTS AND METHODS}

These physiologic studies ${ }^{1}$ were approved by the Royal Women's Hospital Research and Ethics committees. Parental consent for these recordings was obtained.

At the Royal Women's Hospital, Melbourne, spontaneously breathing newly born very preterm infants with respiratory difficulty are assisted with a facemask CPAP. Between 2004 and 2007, we recorded physiologic parameters during delivery room stabilization of very preterm infants. All recordings of infants born at $\leq 32$ wk' gestation, who were spontaneously breathing, while treated with CPAP via a face mask, were identified and their breathing patterns in the first 10 minutes of life were analyzed. Our guidelines recommend to start with a CPAP-level set on $8 \mathrm{cmH}_{2} \mathrm{O}$. Infants were excluded if positive pressure ventilation was given at birth. We only used recordings of infants if there were: a) no signs of mask leak, b) a clean flow signal, not disturbed by secretions or infant movements, and c) no signs of movement of the mask.

Recording equipment. Gas flow in and out of the infant was measured with a hot-wire anemometer (Florian: Acutronic Medical Systems AG, Zug, Switzerland) placed between the T-piece of a resuscitation device (Neopuff Infant Resuscitator, Fisher and Paykel, Auckland, New Zealand) and the facemask. This signal was integrated to derive inspired and expired tidal volume. Airway pressure was measured immediately proximal to the mask. The signals of airway flow, tidal volumes, and airway pressure were digitised and recorded at $200 \mathrm{~Hz}$ using a neonatal respiratory physiologic recording program (Spectra, Grove Medical Limited, Hampton, UK).

Data collection. Demographic data were collected from the hospital records. The total number of breaths analyzed for each infant was noted, including their time after birth. Details of the waveforms of pressure, flow, and tidal volume were carefully analyzed to identify the breathing patterns. Breaths of each pattern were analyzed in detail and the following parameters noted (see also Figures): respiratory rate, inspiration pattern and duration, expiratory hold (the time from zero flow at the end of inspiration to the start of the main expiratory flow), expiratory duration, postexpiratory pause (the time from zero flow at the end of expiration to the start of positive flow at the beginning of inspiration), duration of each breath, peak inspiratory flow, peak expiratory flow; inspiratory and expiratory tidal volumes (15).

Data analysis. Data were analyzed with SPSS (SPSS for windows, version $12.0,2005$, Chicago, IL) and presented as mean (SD) or number (\%) where appropriate.

\section{RESULTS}

Recordings from 103 infants were examined in detail, 91 of these were excluded from analysis for the following reasons: 58 infants were ventilated with mask and bag at the start of resuscitation, 27 recordings showed mask leak and 6 flow signals were disturbed by secretions or movement of the mask. Twelve infants had recordings that were suitable for analysis. Their mean (SD) gestational age was 29 (1.9) weeks, birth weight 1220 (412) $\mathrm{g}$ and median (range) of the 5 min Apgar score was $8(8,9)$. Eleven received prenatal steroids and seven were born by

Abbreviation: CPAP, continuous positive airway pressure 
caesarean section. The mean time for the start of recording the analyzed breaths was $159 \mathrm{~s}$ (range, 26-301) after birth. None of the infants were intubated in the delivery room.

A total of 792 breaths (range, 17-105 per infant) were analyzed. The pattern of inspiration was similar in all breaths with a duration of $0.36(0.11) \mathrm{s}$. There were five different patterns of expiratory flow (Figs. 1-5). Three were characterized by interruption or braking of expiration and were seen in $79 \%(627 / 792)$ of the breaths. They prolonged the expiratory time to $1.6(1.1) \mathrm{s}$. The remaining two patterns were seen in $21 \%(165 / 792)$ of the breaths. These showed no evidence of interruption or braking of expiration and had an expiration time of $0.53(0.13) \mathrm{s}$. The numbers of breaths of each pattern for each patient are shown in Table 1. In most infants, more than one pattern was observed. The respiratory parameters of each pattern are shown in Table 2.

Expiratory hold. In 47\% (372/792) of the breaths expiration was braked to a complete hold, postponing the main expiratory flow (Fig. 1). This pattern was characterized by a period of no expiratory flow ending with a single expiratory flow peak or multiple expiratory flow peaks. Expiration was immediately followed by an inspiration, i.e., there was no postexpiratory pause.

Slow expiration. In 10\% (83/792) of breaths, the expiratory pattern was characterized by an initial low expiratory flow rate ending with a single expiratory flow peak late in expiration and/or frequently interrupted expiratory flow waves (Fig. 2). These were immediately followed by an inspiration.

Crying/grunting. In 22\% (172/792) of the breaths, expiration was slowed by either grunting or crying (Fig. $3 A$ and $B$ ). This pattern was characterized by a large inspiration followed by high frequency interruptions to the expiratory flow wave, ob-

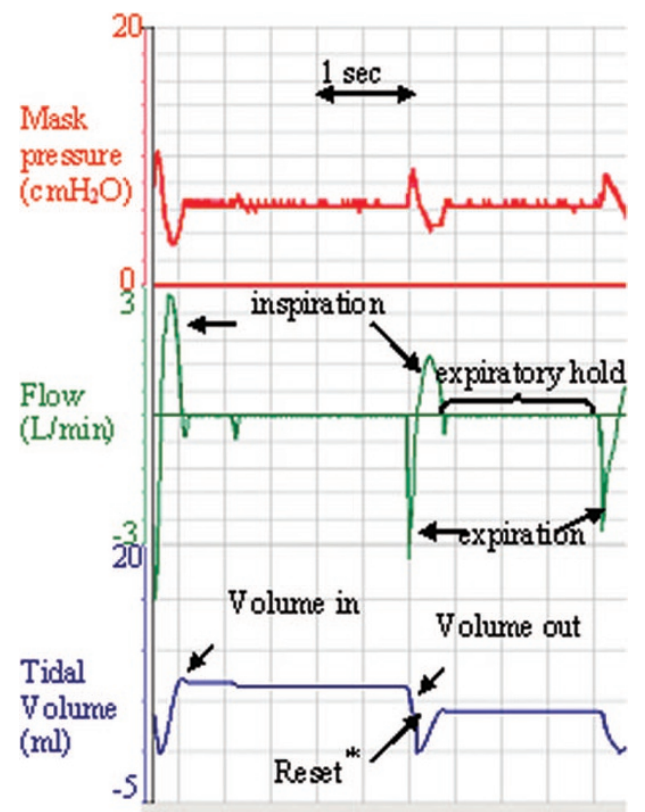

Figure 1. Two examples of the expiratory hold pattern, characterized by a period of no expiratory flow ending with a single expiratory flow peak or multiple expiratory flow peaks. Expiration is immediately followed by an inspiration; there is no postexpiratory pause. *Note that the software setting is that it resets volume trace as soon as expiratory flow trace reaches baseline.

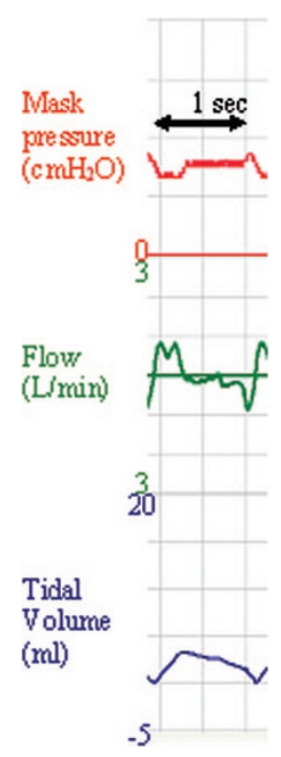

Figure 2. An example of a slow expiration pattern, expiratory flow is slowed or frequently interrupted. Expiration is immediately followed by an inspiration, there is no postexpiratory pause.

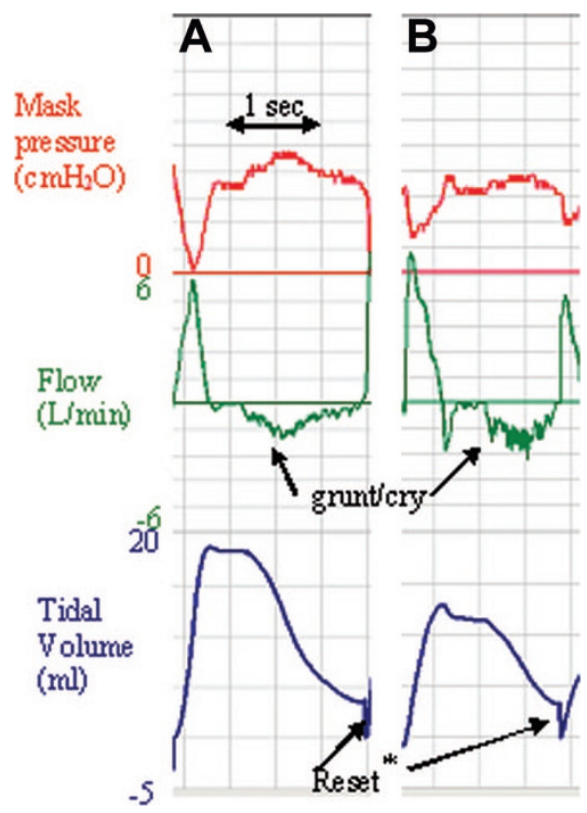

Figure 3. $A, B$. Two examples from patient 11 with the crying/grunting pattern (scale of flow is doubled to fit peak inspiratory flow rate). In both breaths expiration is slowed down and a noise signal with high frequency is visible. *Note that the software setting is that it resets volume trace as soon as expiratory flow trace reaches baseline.

served as a noise signal in the wave. Expiration was then immediately followed by inspiration. We categorized crying and grunting as one pattern as it was difficult in most cases to distinguish between them from the recording and we did not record sound.

Patterns where expiration was not braked. In 21\% (165/ 792) of the breaths, an unbraked or normal expiratory pattern was seen (Figs. 4 and 5). This was characterized by uninterrupted expiration with peak expiratory flow early in expiration. Expiration was not prolonged (I:E time approximately $1: 1.5)$ although sometimes the expiratory flow was followed by an expiratory pause before the next inspiration (Fig. 4). In $91 / 165$ of these breaths, the pattern was characterized by a 


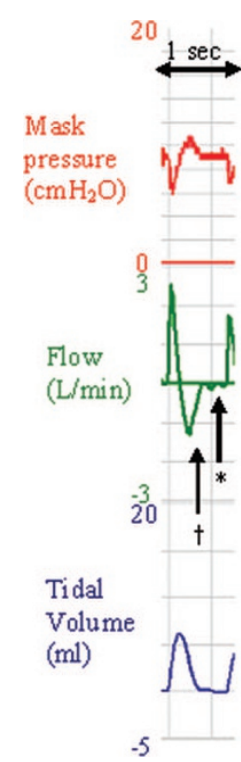

Figure 4. An example of a normal expiratory pattern without braking, characterized by a peak expiratory flow $\dagger$ at the beginning of expiration and showing a postexpiratory pause*.

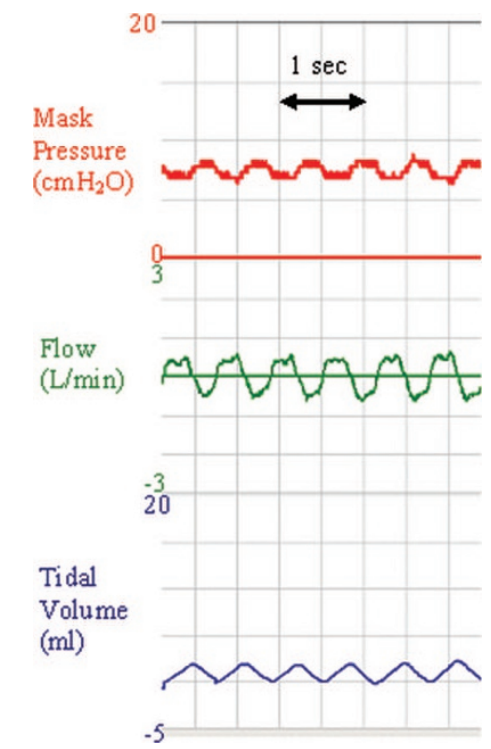

Figure 5. An example of panting pattern with respiratory rate of $96 / \mathrm{min}$, tidal volume $2 \mathrm{~mL} / \mathrm{kg}$ and expiratory time is approximately equal to inspiratory time.

respiratory rate greater than $60 / \mathrm{min}$ by shortening the expiratory time (I:E time to approximately 1:1) and small tidal volumes. In these breaths, there was no postexpiratory pause before inspiration. We named this the panting pattern (Fig. 5).

\section{DISCUSSION}

Most of the breaths of these very preterm infants, recorded in the minutes after birth, were characterized by interruption, or braking, of the expiratory flow. This slowed or even stopped the expiration and increased the expiratory time. Slow expiration, grunting/crying, and the expiratory hold pattern each represent different forms of expiratory braking (16-23). These patterns were shown to prevent a loss of lung volume during expiration in older term (16-23) and preterm infants $(19,20)$.
Airflow is controlled throughout the breathing cycle by reflex action of diaphragmatic and laryngeal muscle activity (24-30). These reflexes are present at birth in term and preterm infants and have a crucial role in the control of breathing and lung volume (22,31-37). There are two mechanisms for stopping or slowing expiratory flow and maintaining an elevated lung volume during expiration. The first is diaphragmatic postinspiratory activity, which slows the rate of lung deflation by counteracting its passive recoil $(16-20)$. The second is by closure or narrowing of the larynx $(19,21-23)$. The expiratory noise associated with vocal cord adduction, i.e., grunting has been recognized as a dynamic braking of expiration by the larynx $(22,38)$. In absence of an audible grunt, the larynx still maintains a dynamic role in slowing expiration (27).

The pattern that we most frequently observed, the expiratory hold pattern, has similar characteristics to the first breaths observed in term infants at birth $(13,39,40)$. After inspiration, gas is held in the lung under pressure by laryngeal adduction braking the expiratory flow. This has also been observed in preterm and term infants during spontaneous breathing later in life, but did not occur as frequently as in our study $(16-19,22,23,38)$.

During braked expiration, the closed or narrowed glottis, with increased intra-pulmonary pressure from abdominal muscle contraction, causes the airway pressure to be maintained above atmospheric. This could represent an important force for clearing the fluid from the lung, facilitating distribution of gas within the lung, and splinting the alveoli and airways open $(9,10,13,14,22,39)$.

Another strategy infants can use to increase end-expiratory volume is a high respiratory rate. This was seen in the panting pattern. The shortened expiratory time reduces the time for gas to leave the lung (35).

The spontaneous gas flow patterns we observed are different from those seen when manual inflations are given during neonatal resuscitation (Fig. 6). The neonatal resuscitation guidelines do not mandate any particular ventilation pattern, although they do suggest a rate of $40-60 / \mathrm{min}$ (41). Prolonged inflations are mentioned but not mandated for the initial breaths (41). This study demonstrates that very preterm infants have specific mechanisms to inflate their lungs and try to keep them inflated immediately after birth. It is possible that a similar strategy used during the initial resuscitation of a preterm infant who is apnoeic or breathes insufficiently, i.e., inflation followed by a hold and a short expiration, may be more effective than traditional techniques which use a short inspiratory time and no hold.

Making recordings of how very preterm infants breathe immediately after birth is very difficult. Because of the constraints of not interfering with the infant's care or resuscitation and yet applying a facemask with a pneumotachograph and CPAP device attached, as soon as possible after birth, limited the number of infants that could be recorded in the time available and the number of recordings that could be made. This is an area of research where it is not possible to study large numbers in detail and obtaining a recording of sufficient quality for analysis limited the number of inflations that could be studied. In particular, it caused a large variation in the number of breaths 
Table 1. Number of each type of breathing pattern for each infant

\begin{tabular}{|c|c|c|c|c|c|c|c|}
\hline Infant & Gestation (wk) & Expiratory hold & Crying/grunting & Slow expiration & Panting & Unbraked expiration, normal respiratory rate & Total \\
\hline 1 & 26 & 49 & 10 & 5 & 2 & 2 & 68 \\
\hline 2 & 28 & 22 & 0 & 0 & 0 & 0 & 22 \\
\hline 3 & 28 & 32 & 5 & 1 & 0 & 0 & 38 \\
\hline 4 & 30 & 8 & 0 & 1 & 31 & 2 & 42 \\
\hline 5 & 29 & 37 & 5 & 1 & 12 & 0 & 55 \\
\hline 6 & 29 & 58 & 28 & 10 & 5 & 3 & 104 \\
\hline 7 & 27 & 46 & 0 & 10 & 18 & 15 & 89 \\
\hline 8 & 27 & 5 & 11 & 0 & 11 & 51 & 78 \\
\hline 9 & 32 & 42 & 16 & 37 & 2 & 1 & 98 \\
\hline 10 & 29 & 56 & 22 & 17 & 10 & 0 & 105 \\
\hline 11 & 32 & 10 & 66 & 0 & 0 & 0 & 76 \\
\hline 12 & 28 & 7 & 9 & 1 & 0 & 0 & 17 \\
\hline Total & & 372 & 172 & 83 & 91 & 74 & 792 \\
\hline
\end{tabular}

Table 2. Respiratory parameters for each breathing patterns for all infants

\begin{tabular}{|c|c|c|c|c|c|}
\hline Parameter mean (SD) & $\begin{array}{c}\text { Expiratory hold } \\
n=372\end{array}$ & $\begin{array}{c}\text { Slow } \\
\text { expiration } \\
n=83\end{array}$ & $\begin{array}{c}\text { Crying/grunting } \\
n=172\end{array}$ & $\begin{array}{l}\text { Unbraked expiration, normal } \\
\text { respiratory rate } \\
n=84\end{array}$ & $\begin{array}{l}\text { Panting } \\
n=81\end{array}$ \\
\hline Respiratory rate $\left(\mathrm{min}^{-1}\right)$ & $32(11)$ & $48(16)$ & $42(18)$ & $54(4)$ & $88(18)$ \\
\hline Inspiratory time (sec) & $0.36(0.10)$ & $0.34(0.15)$ & $0.38(0.14)$ & $0.40(0.08)$ & $0.34(0.07)$ \\
\hline Expiratory hold (sec) & $1.53(1.10)$ & 0 & 0 & 0 & 0 \\
\hline Expiratory time $(\mathrm{sec})^{*}$ & $1.85(1.14)$ & $1.10(0.90)$ & $1.30(0.75)$ & $0.65(0.11)$ & $0.41(0.14)$ \\
\hline Postexpiratory pause (sec) & 0 & 0 & 0 & $0.07(0.03)$ & 0 \\
\hline Peak inspiratory flow $(\mathrm{ml} / \mathrm{s})$ & $32(16)$ & $29(130)$ & $63(37)$ & $22(9)$ & $20(10)$ \\
\hline Peak expiratory flow $(\mathrm{ml} / \mathrm{s})$ & $-42(30)$ & $-24(14)$ & $-36(24)$ & $-19(15)$ & $-18(12)$ \\
\hline Tidal volume $(\mathrm{ml} / \mathrm{kg})$ & $5.8(4.1)$ & $3.5(2.3)$ & $7.5(4.2)$ & $4.2(1.5)$ & $3.1(1.7)$ \\
\hline
\end{tabular}

* Expiratory time of expiratory hold pattern is time of expiration plus duration of the hold.

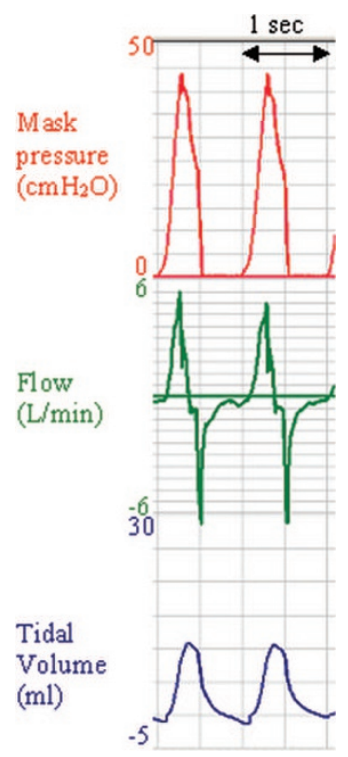

Figure 6. Part of a recording of resuscitation of a neonate born at $26 \mathrm{wk}$ gestation showing two inflations with Laerdal mask and bag. Inspiration is immediately followed by expiration, with no expiratory hold or pause.

analyzed per infant. Analyzing a longer breath sequence over a longer period would have been ideal but was not practical. Future studies should endeavor to achieve this. Similar studies immediately after birth done by Karlberg et al. (39), Milner and Sauders (9), and Mortola et al. (13) also recorded a limited number of breaths in small groups of patients.

Our observation could be biased by the practical difficulties of making respiratory recordings immediately after birth. Our neonatal resuscitation research team has extensive experience in making physiologic recordings and recognized it was very difficult to get long recordings without ventilation, mask leak, movement of the mask or patient, secretions, etc. All recordings with artifacts have been excluded from analysis and as expected, only a minority of recordings was suitable for inclusion in this study. Both small number of recordings and the wide range of analyzed breaths per infant could have led to a bias. Therefore, we cannot assume that the patterns observed in this study represent the patterns of all spontaneously breathing preterm infants. Nevertheless, they are similar to those described in newly born term infants $(13,39,40)$ and in older preterm infants $(19,20)$.

Although a mask on the face is a standard procedure for delivering positive airway pressure to infants after birth it might influence the breathing pattern by stimulating respiratory reflexes and thereby influence the tidal volume and respiratory rate $(42,43)$. However, it is impossible to measure inspiratory and expiratory flows and tidal volumes in this situation without use of face mask $(44,45)$. Previous studies reported no adverse effects of a face mask during the first breaths (7-14). It is possible that the added dead space of the face mask caused carbon dioxide accumulation and influenced the breathing pattern $(46,47)$. However, the wide diameter of the mask reduced rebreathing and firm application of the mask reduced the dead space (15).

In these very preterm infants, it was not appropriate to use a facemask without also providing CPAP. The use of CPAP might have influenced the breathing pattern. However, the patterns we have recorded are similar to some breathing patterns described in term infants at birth without CPAP $(13,39,40)$. 
A nCPAP of $8 \mathrm{~cm} \mathrm{H}_{2} \mathrm{O}$ was used for several reasons. Studies show a distending pressure is important for maintaining FRC (48), increasing lung compliance and improving oxygenation, and that $8 \mathrm{~cm} \mathrm{H}_{2} \mathrm{O}$ is more effective than a lower pressure (49). Studies have used pressures up to $10 \mathrm{~cm}_{2} \mathrm{O}$ (50) and Gregory et al.(51) used a nCPAP pressure up to $12 \mathrm{~mm} \mathrm{Hg}$. Immediately after birth is the time when most assistance is needed to develop and maintain an FRC because the lungs are fluid filled and the lungs are stiff. It is likely that a relatively high pressure may be necessary in the first few minutes. Animal studies show that a pressure of $8 \mathrm{~cm} \mathrm{H}_{2} \mathrm{O}$ improves oxygenation and reduces lung injury better than lower pressures $(52,53)$. The optimum nCPAP pressure for treating individual very preterm infants from birth is unknown.

In conclusion, this is the first study reporting the spontaneous breathing patterns in very preterm infants in the minutes after birth. We frequently observed prolongation of expiration in very preterm infants treated with facemask CPAP immediately after birth, predominantly characterized by a breath hold. This braking of expiration is recognized as an attempt to defend lung volume. Our speculation is that techniques of positive pressure ventilation that mimic expiratory braking might improve the effectiveness of respiratory support in the delivery room.

\section{REFERENCES}

1. Gerhardt T, Bancalari E 1980 Chestwall compliance in full-term and premature infants. Acta Paediatr Scand 69:359-364

2. Heldt GP, Mcllroy MB 1987 Dynamics of chest wall in preterm infants. J Appl Physiol 62:170-174

3. Barker PM, Gowen CW, Lawson EE, Knowles MR 1997 Decreased sodium ion absorption across nasal epithelium of very premature infants with respiratory distress syndrome. J Pediatr 130:373-377

4. Zelenina M, Zelenin S, Aperia A 2005 Water channels (aquaporins) and their role for postnatal adaptation. Pediatr Res 57:47R-53R

5. Aly H, Massaro AN, Patel K, El Mohandes AA 2005 Is it safer to intubate premature infants in the delivery room? Pediatrics 115:1660-1665

6. Thomson MA 2002 Continuous positive airway pressure and surfactant; combined data from animal experiments and clinical trials. Biol Neonate 81:16-19

7. Karlberg P, Koch G 1962 Respiratory studies in newborn infants. III. Development of mechanics of breathing during the first week of life. A longitudinal study. Acta Paediatr Suppl 135:121-129

8. Karlberg P 1960 The adaptive changes in the immediate postnatal period, with particular reference to respiration. J Pediatr 56:585-604

9. Milner AD, Sauders RA 1977 Pressure and volume changes during the first breath of human neonates. Arch Dis Child 52:918-924

10. Vyas H, Milner AD, Hopkins IE 1981 Intrathoracic pressure and volume changes during the spontaneous onset of respiration in babies born by cesarean section and by vaginal delivery. J Pediatr 99:787-791

11. Vyas H, Milner AD, Hopkin IE, Falconer AD 1983 Role of labour in the establishment of functional residual capacity at birth. Arch Dis Child 58:512-517

12. Vyas H, Field D, Milner AD, Hopkin IE 1986 Determinants of the first inspiratory volume and functional residual capacity at birth. Pediatr Pulmonol 2:189-193

13. Mortola JP, Fisher JT, Smith JB, Fox GS, Weeks S, Willis D 1982 Onset of respiration in infants delivered by cesarean section. J Appl Physiol 52:716-724

14. Saunders RA, Milner AD 1978 Pulmonary pressure/volume relationships during the last phase of delivery and the first postnatal breaths in human subjects. J Pediatr 93:667-673

15. Stick S 1996 Measurements during tidal breathing. In: Stocks J, Sly PD, Tepper RS, Morgan WJ (eds) Infant Respiratory Function Testing. New York: John Wiley \& Sons Inc, pp 118-119

16. Kosch PC, Stark AR 1984 Dynamic maintenance of end-expiratory lung volume in full-term infants. J Appl Physiol 57:1126-1133

17. Lopes J, Muller NL, Bryan MH, Bryan AC 1981 Importance of inspiratory muscle tone in maintenance of FRC in the newborn. J Appl Physiol 51:830-834

18. Mortola JP, Milic-Emili J, Noworaj A, Smith B, Fox G, Weeks S 1984 Muscle pressure and flow during expiration in infants. Am Rev Respir Dis 129:49-53

19. Radvanyi-Bouvet MF, Monset-Couchard M, Morel-Kahn F, Vicente G, DreyfusBrisac C 1982 Expiratory patterns during sleep in normal full-term and premature neonates. Biol Neonate 41:74-84

20. Stark AR, Cohlan BA, Waggener TB, Frantz ID III, Kosch PC 1987 Regulation of end-expiratory lung volume during sleep in premature infants. J Appl Physiol 62:1117-1123
21. Milner AD, Saunders RA, Hopkin IE 1978 Is air trapping important in the maintenance of the functional residual capacity in the hours after birth? Early Hum Dev 2:97-105

22. Fisher JT, Mortola JP, Smith JB, Fox GS, Weeks S 1982 Respiration in newborns: development of the control of breathing. Am Rev Respir Dis 125:650-657

23. Mortola JP, Magnante D, Saetta M 1985 Expiratory pattern of newborn mammals. J Appl Physiol 58:528-533

24. Kosch PC, Hutchinson AA, Wozniak JA, Carlo WA, Stark AR 1988 Posterior cricoarytenoid and diaphragm activities during tidal breathing in neonates. J Appl Physiol 64:1968-1978

25. Kosch PC, Davenport PW, Wozniak JA, Stark AR 1985 Reflex control of expiratory duration in newborn infants. J Appl Physiol 58:575-581

26. England SJ, Kent G, Stogryn HA 1985 Laryngeal muscle and diaphragmatic activities in conscious dog pups. Respir Physiol 60:95-108

27. Harding R, Johnson P, McClelland ME 1980 Respiratory function of the larynx in developing sheep and the influence of sleep state. Respir Physiol 40:165-179

28. Farber JP 1978 Laryngeal effects and respiration in the suckling opossum. Respir Physiol 35:189-201

29. Henderson-Smart DJ, Johnson P, McClelland ME 1982 Asynchronous respiratory activity of the diaphragm during spontaneous breathing in the lamb. J Physiol 327:377-391

30. MacFarlane PM, Frappell PB, Mortola JP 2002 Mechanics of the respiratory system in the newborn tammar wallaby. J Exp Biol 205:533-538

31. Paintal AS 1969 Mechanism of stimulation of type J pulmonary receptors. J Physiol 203:511-532

32. Coleridge HM, Coleridge JC 1994 Pulmonary reflexes: neural mechanisms of pulmonary defense. Annu Rev Physiol 56:69-91

33. Widdicombe JG 1964 Respiratory reflexes. In: Fenn W, Rahn H (eds) Handbook of Physiology, Section 3, Respiration. Vol. 2. Washington, DC: American Physiological Society, pp 585-630

34. Cross KW, Klaus M, Tooley WH, Weisser K 1960 The response of the new-born baby to inflation of the lungs. J Physiol 151:551-565

35. Olinsky A, Bryan MH, Bryan AC 1974 Influence of lung inflation on respiratory control in neonates. J Appl Physiol 36:426-429

36. Hannam S, Ingram DM, Rabe-Hesketh S, Milner AD 2001 Characterisation of the Hering-Breuer deflation reflex in the human neonate. Respir Physiol 124:51-64

37. Hannam S, Ingram DM, Milner AD 1998 A possible role for the Hering-Breuer deflation reflex in apnea of prematurity. J Pediatr 132:35-39

38. Lindroth M, Johnson B, Ahlstrom H, Svenningsen NW 1981 Pulmonary mechanics in early infancy. Subclinical grunting in low-birth-weight infants. Pediatr Res 15:979-984

39. Karlberg P, Cherry RB, Escardo FE, Koch G 1962 Pulmonary ventilation and mechanics of breathing in the first minutes of life, including the onset of respiration. Acta Paediatr Scand 51:121-136

40. Engstrom L, Karlberg P, Rooth G, Tunell R 1966 The Onset of Respiration, a Study of Respiration and Changes in Blood Gases and Acid-Base Balance. New York: Association for the aid of crippled children, pp 17-23

41. The International Liaison Committee on Resuscitation 2006 The International Liaison Committee on Resuscitation (ILCOR) consensus on science with treatment recommendations for pediatric and neonatal patients: neonatal resuscitation. Pediatrics 117:e978-e988

42. Fleming PJ, Levine MR, Goncalves A 1982 Changes in respiratory pattern resulting from the use of a facemask to record respiration in newborn infants. Pediatr Res 16:1031-1034

43. Dolfin T, Duffty P, Wilkes D, England S, Bryan H 1983 Effects of a face mask and pneumotachograph on breathing in sleeping infants. Am Rev Respir Dis 128:977-979

44. Stocks J 1999 Lung function testing in infants. Pediatr Pulmonol Suppl 18:14-20

45. Schmalisch G, Foitzik B, Wauer RR, Stocks J 2001 Effect of apparatus dead space on breathing parameters in newborns: "flow-through" versus conventional techniques. Eur Respir J 17:108-114

46. Marsh MJ, Ingram D, Milner AD 1993 The effect of instrumental dead space on measurement of breathing pattern and pulmonary mechanics in the newborn. Pediatr Pulmonol 16:316-322

47. Morris MG 1999 A simple new technique to measure the effective dead space of the face mask with a water volumeter in infants. Eur Respir J 14:1163-1166

48. Thome U, Topfer A, Schaller P, Pohlandt F 1998 The effect of positive endexpiratory pressure, peak inspiratory pressure, and inspiratory time on functional residual capacity in mechanically ventilated preterm infants. Eur J Pediatr 157:831-837

49. Elgellab A, Riou Y, Abbazine A, Truffert P, Matran R, Lequien P, Storme L 2001 Effects of nasal continuous positive airway pressure (NCPAP) on breathing pattern in spontaneously breathing premature newborn infants. Intensive Care Med 27:1782-1787

50. Kamper J, Ringsted C 1990 Early treatment of idiopathic respiratory distress syndrome using binasal continuous positive airway pressure. Acta Paediatr Scand 79:581-586

51. Gregory GA, Kitterman JA, Phibbs RH, Tooley WH, Hamilton WK 1971 Treatment of the idiopathic respiratory-distress syndrome with continuous positive airway pressure. N Engl J Med 284:1333-1340

52. Probyn ME, Hooper SB, Dargaville PA, McCallion N, Harding R, Morley CJ 2005 Effects of tidal volume and positive end-expiratory pressure during resuscitation of very premature lambs. Acta Paediatr 94:1764-1770

53. Mulrooney N, Champion Z, Moss TJ, Nitsos I, Ikegami M, Jobe AH 2005 Surfactant and physiological responses of preterm lambs to continuous positive airway pressure. Am J Respir Crit Care Med 171:488-493 